\title{
Potential Impact of Consumer Intention on Generation of Waste Photovoltaic Panels: A Case Study for Tokyo
}

\author{
Shinsuke Murakami ${ }^{1,2, *(\mathbb{D}, \text { Haruhisa Yamamoto }}{ }^{2}$ and Terufumi Toyota ${ }^{2}$ \\ 1 Department of Technology Management for Innovation, Graduate School of Engineering, The University of \\ Tokyo, Tokyo 113-8656, Japan \\ 2 Department of Systems Innovation, Graduate School of Engineering, The University of Tokyo, \\ Tokyo 113-8656, Japan; yamamoto-haruhisa202@g.ecc.u-tokyo.ac.jp (H.Y.); tell7714@outlook.jp (T.T.) \\ * Correspondence: smurakam@tmi.t.u-tokyo.ac.jp
}

Citation: Murakami, S.;

Yamamoto, H.; Toyota, T. Potential Impact of Consumer Intention on Generation of Waste Photovoltaic Panels: A Case Study for Tokyo. Sustainability 2021, 13, 10507. https://doi.org/10.3390/ su131910507

Academic Editor: Dimitrios Komilis

Received: 31 August 2021

Accepted: 21 September 2021

Published: 22 September 2021

Publisher's Note: MDPI stays neutral with regard to jurisdictional claims in published maps and institutional affiliations.

Copyright: (c) 2021 by the authors. Licensee MDPI, Basel, Switzerland. This article is an open access article distributed under the terms and conditions of the Creative Commons Attribution (CC BY) license (https:// creativecommons.org/licenses/by/ $4.0 /)$.

\begin{abstract}
As the world moves toward decarbonization, Japan is experiencing a rapid introduction of solar modules. However, the country does not have an adequate social system for managing waste photovoltaic (PV) panels. A waste generation estimate would be needed to do this effectively. Usually, waste generation estimation is performed by assuming that the lifespan distribution is primarily dependent on the mechanical life of the target item. However, considering the continuing improvement in panel quality, consumers consider replacement or disposal before mechanical failure of the product. Therefore, to study consumer intention, we surveyed potential consumer decision making on replacement/disposal via a questionnaire survey and attempted to include the result as part of our waste panel generation estimation, which, to our knowledge, has never previously been carried out. Considering the owners' decision making, waste panel generation was in advance compared with the case where we only assumed the mechanical failure of panels and housings. This indicated a huge number of potentially reusable panel generations. In addition to mechanical failure, waste panel generation due to owners' decisions should also be considered for estimating maximum potential waste. Policy makers should prepare the appropriate recycling social system in advance, considering the possible reuse of panels, which fits the current social situation oriented toward a circular economy.
\end{abstract}

Keywords: waste PV panels; generation forecast; consumer's intention; Tokyo

\section{Introduction}

As decarbonization has become crucial to humanity, the introduction of renewable energy is accelerating. Since the day of the 2011 Great East Japan Earthquake and Tsunami, Japan can no longer rely on nuclear power after the tragic events of Fukushima, forcing the country to turn to large-scale adoption of renewable energy in policy terms. The introduction of the feed-in-tariff (FIT) system in particular has led to the rapid introduction of renewable energy. Solar power generation installations in Japan have made rapid progress since 2011 [1].

While photovoltaic (PV) modules provide clean energy, there are multiple concerns regarding the material cycle perspective, including the raw material demand and end-of-life (EOL) management. With regard to raw materials, PV panels often demand critical minor metals. These demands may be constraints for the introduction of PV modules [2,3]. From the EOL management perspective, the biggest concern is that voluntary recycling is not likely to occur because of its poor economic viability. This is technically possible, although it is economically difficult. Many researchers have tackled this issue by developing new technologies [4]. While it is necessary to confirm the contribution of PV technology to climate change mitigation, in view of its potential toxicity, life cycle assessment (LCA) is an important research topic. Reverse logistics (RL) design is another, because effective RL can 
contribute toward climate change mitigation and increase the economic viability of whole EOL management systems [5,6].

Considering the low economic feasibility and potential toxicity, designing an appropriate EOL management system for waste PV panels is an important social task. However, Japan has not yet prepared any relevant system and, currently, the panels are managed within the usual industrial waste management system, and more PV-specific systems are awaited.

In general, to design a future waste management system, reliable waste generation scenarios are required. Waste generation is often estimated by modeling the lifespan, or more precisely, the duration of use of the product. In the case of already matured goods with a sufficient amount of data from real wastes, assuming a parametric lifespan distribution and statistically estimating the parameters is the most widely used approach [7,8]. However, in the case of PV panels, data are limited for statistical analysis; therefore, we need to estimate the parameters in different ways. PV panels degrade gradually; therefore, assuming the degradation rate and trying to fit it to the specific probability distribution, such as Weibull or log-normal, is a possible approach $[9,10]$. One of the most cited estimates is that of the International Renewable Energy Agency (IRENA) [11]. There are also some country-specific waste generation forecasts. Paiano [12] makes an estimate that assumes that PV panels have a lifespan of 25 years, whereas Santos and AlonsoGarcía [13] apply the Weibull distribution and obtain parameters from the IRENA study.

These studies estimated the life of PV panels, mainly with knowledge of mechanical life. However, depending on the owners' decision making, these panels can reach EOL before failure. Recently, the impact of user intention or behavior on the duration of product use has drawn attention $[14,15]$. Owing to the continuous improvement of PV modules, replacing existing panels with new ones generates more electricity and therefore more profits, even with the replacement cost. In addition, the limited period of the FIT system (10 years for housing with less than $10 \mathrm{~kW}$ capacity) can be another reason why owners may consider replacing their panels before mechanical failure occurs.

In this study, we attempted to quantify the potential impact of owners' decision making regarding waste PV panel generation, which, to our knowledge, has never been previously carried out for PV panels. We chose Tokyo as our case study region and considered rooftop panels for housing, which is a case that has never been studied before. Our study shows that if the impact is huge and a significant amount of waste will generate much earlier than the existing estimation, we must prepare the social system for EOL management to address it. Furthermore, we can estimate the amount of EOL unbroken PV panels, which might be reusable. This is another important contribution of this study to design the effective PV-specific EOL management system.

\section{Materials and Methods}

\subsection{Case and Data}

As mentioned, we chose rooftop PV panels for housing in Tokyo Metropolitan City as our case study. There were multiple reasons for selecting this as our case study. First, Japan has not yet established its EOL PV panel management system, whereas some countries already have, such as the EU's waste electrical and electronic equipment (WEEE) directive. Second, Tokyo has an incredibly high population density. According to the Tokyo metropolitan government, on 1 May 2021, the average population density is 6364 people per square kilometer. Toshima ward, which is located in the central part of Tokyo prefecture, has a population density of 22,861 people per square kilometer. The population of the prefecture is close to 14 million, and the number of its households is more than 7 million. Waste management in crowded cities is a difficult task. Waste PV panel generation from households has a different impact than that from large commercial solar power plants; that is, small quantities of waste generated by a large number of independent decision makers, based on a variety of decisions that are not purely commercial. The third reason was the rapid diffusion of rooftop PV panels in Japan. With the introduction of FIT in 2012, a large 
number of solar modules were added during the next couple of years. Considering that the FIT rate was designed to decrease dramatically, it seems natural that many tried to introduce it as soon as possible.

As explained in Section 2.2, we conducted multiple surveys and estimated the future generation scenarios of waste PV panels trying to reflect household decision making based on factors other than mechanical failures. Therefore, future installation scenarios were required to be identified. We followed the Japan Photovoltaic Energy Association (JPEA) scenarios for all of Japan [1] and allocated them proportionally using the share of installed capacity in each municipality in Tokyo prefecture as of March 2019 and estimated future installation from 2019 to 2060.

\subsection{Survey Designs}

\subsubsection{Survey to Stakeholders}

Our ultimate goal was to quantify the potential impact of consumer decision making on future waste PV panel generation. Therefore, we designed a questionnaire survey for consumers to identify the circumstances in which they may dispose of their panels before mechanical failure. However, it was difficult for us to list the candidate circumstances; therefore, we conducted interviews with the following stakeholders: the Tokyo Metropolitan Government; PV manufacturers; engineering, procurement, and construction (EPC) contractors; and housing makers.

The survey revealed the following four main scenarios in which consumers considered disposal/replacement of their PV panels. The first scenario was at the end of the FIT period, which is 10 years for most households. The second scenario was at the end of the payback period. Some consumers had their own idea of the payback period, while others were informed by sellers of when they installed their panels. In some cases, the sellers tried to promote replacement with the new ones, which could be an additional motivation for panel owners. We assumed that this promotion at the end of the payback period was the third scenario. The fourth scenario was the intended duration of use by consumers themselves. According to our survey, some consumers had an expectation of how many years their panels would continue to work. Consumers considered their replacement/disposal when their ideal lifespan was reached, even if the panels had not failed. Based on the above-mentioned scenarios we prepared a questionnaire to conduct the survey among the consumers to understand their replacement/disposal behaviors.

\subsubsection{Questionnaire Survey to Users}

As mentioned, the questionnaire survey was designed to understand consumers' behaviors with regard to the aforementioned scenarios, i.e., when consumers considered disposing/replacing their panels. The questionnaire survey was conducted only among respondents who had previously installed solar panels on their houses. The survey was conducted online from November to December 2019. Respondents were recruited with the help of a survey company (Macromill Corp., Tokyo). They were taken based on two conditions, whether they were 25 years of age or older, and whether they were residents in the Tokyo metropolitan region at the time of the survey. The total number of respondents was 1032. The questionnaires are presented in Appendix A.

\subsection{Waste Generation Estimation}

Usually, waste generation estimation is carried out by assuming one lifespan distribution and applying it to installation scenarios. However, in this study, there were three reasons for waste generation that needed to be considered. The first was the mechanical failure of the panels. The second was the lifespan of the houses. The last was the consumers' behavior. It was impossible to assume a single lifespan distribution to integrate all three factors; therefore, we needed to carry out a simulation.

The following factors were examined for a set of panels installed on the rooftops; the year of installation, the age of the house, and the owner's age. The last factor was the only 
demographic variable that has a statistically significant influence on disposal/replacement behavior. The details are presented in Section 3.1.

For waste generation, we can apply a widely used population balance model with the assumption of lifespan distribution [16]. Let $T$ be the lifetime of an object and $f(t)$ its probability density function (pdf), then the survival function, $S(t)$, and hazard function, $h(t)$, are

$$
\begin{gathered}
S(t)=\operatorname{Pr}(T>t)=1-F(t)=1-\int_{0}^{t} f(t) d t \\
h(t)=\frac{f(t)}{S(t)}=-\frac{d}{d t}[\log S(t)]
\end{gathered}
$$

Regarding the mechanical failure of the panels, following the baseline scenario of the IRENA report [11], the lifespan distribution is assumed to be a Weibull distribution with a shape parameter of 5.25. The report also assumed 30 years of lifespan. However, this 30-year period included many factors other than PV panel failure. In our interview survey of manufacturers, most interviewees agreed that it is safe to call it broken if the panel's power generation efficiency was less than 50\%. JPEA reported in its presentation at the government's council meeting [17] that the annual degradation of the efficiency is $0.27 \%$, while the Japanese Ministry of Environment states that it fluctuates between $0.5 \%$ and $1 \%$ [18]. Assuming that this annual degradation is $0.5 \%$, the panel's efficiency is less than $50 \%$ in 57 years. Therefore, we prepared two scenarios for average lifespan: 30 and 57 years.

For housing, we adopted the work of Omi [19], who estimated the Weibull distribution, whose shape and scale parameters for wooden structure housing are 2.96 and 62.50 , respectively. In addition, our model also considered the owner's decision making regarding replacement/disposal. From the questionnaire survey, we obtained the share of respondents who considered replacement/disposal under the four scenarios described in Section 2.2.1. With these results, combined with the failure of both panels and housing, we estimated the discrete $f(t)$ for the eventual panel's pdf for each year $(\mathrm{t})$. The details are described in the Results section along with the results of the questionnaire survey.

By subtracting the amount of mechanically failed waste panels, $W_{f}(t)$, from the total waste panel generated, $W(t)$, we calculated the potential reusable waste panels, $R(t)$.

$$
R(t)=W(t)-W_{f}(t)
$$

$R(t)$ : Amount of potentially reusable waste panel generated.

$W(t)$ : Total amount of waste panel generation in year $t$.

$W_{f}(t)$ : Amount of waste panel generation by panel failure.

\section{Results}

\subsection{Questionnaire Survey}

As mentioned in the Methods (Section 2.2.2), the number of respondents was 1032. However, we identified 303 respondents who were not involved in the decision-making process of installation. Therefore, excluding these responses, we analyzed 729 responses.

The primary objective of this survey was to prepare the pdf of PV panel life, by decision making of the owners' to the four scenarios: end of the FIT period, end of the payback period, promotion by sellers at the end of the payback period, and expected ideal duration of panel use.

First, we found that a non-negligible number of owners considered replacement/ disposal during all four scenarios. For each scenario, the shares of the respondents who considered replacement or disposal were $23.05 \%, 21.81 \%, 23.59 \%$, and $30.73 \%$, respectively. We also analyzed which demographic variables caused statistically significant differences in decision making. The share of respondents who considered replacement or disposal at all four scenarios is shown in Figure 1. In Figure 1a, respondents are categorized by age, while gender and marital status are shown in Figure 1b. Among the four age groups studied, 
respondents of age group between 25-39 considered higher replacement or disposal of $\mathrm{PV}$ panels under all the four scenarios (Figure 1a). There was no significant difference in the proportion of responses based on variables, gender, and marital status (Figure 1b). We carried out Pearson's chi-square tests, and the test supported our findings (Table 1). In the following estimates, we tried to utilize this age group information as much as possible.

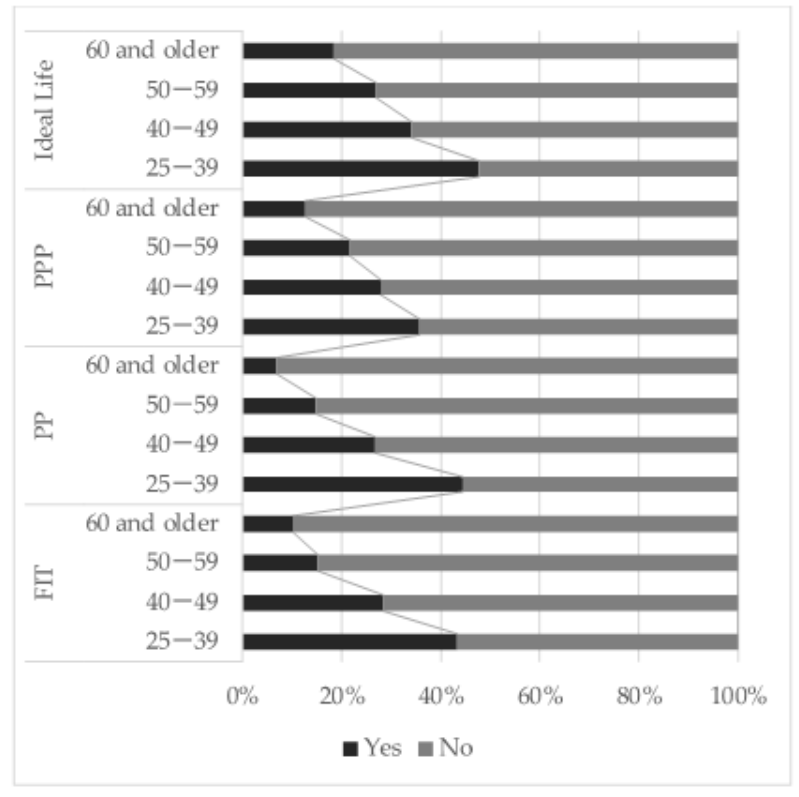

(a)

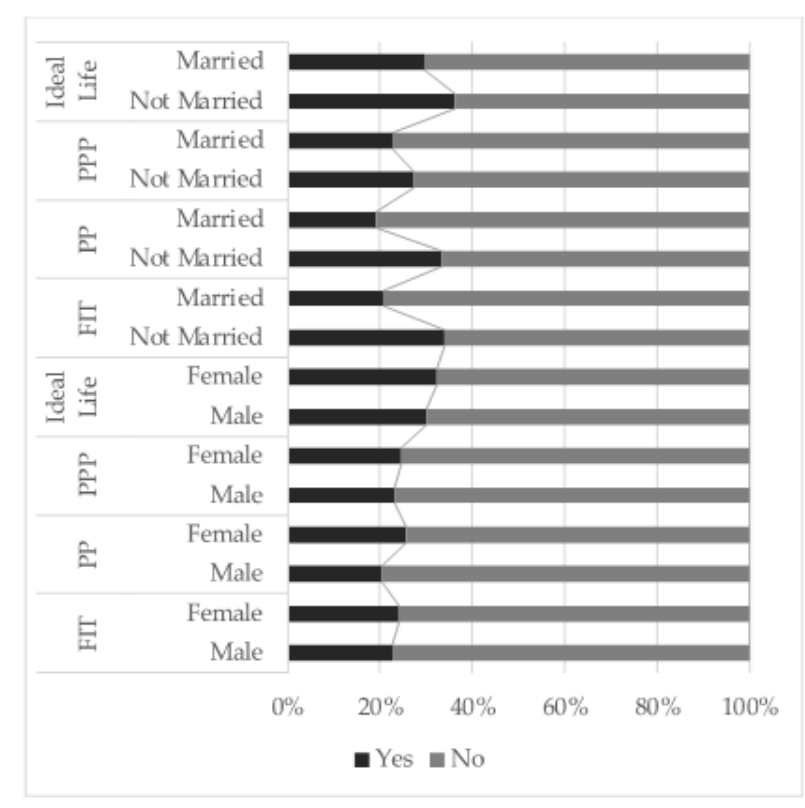

(b)

Figure 1. Share of respondents considering replacement/disposal for each of the four scenarios by three demographic variables; (a) by age group and (b) by gender and marital status. FIT, PP, and PPP denote the end of the feed-in-tariff (FIT) period, the end of the payback period (PP), and the promotion at the end of the payback period (PPP.)

Table 1. The result of Chi-square test for age groups and four scenarios.

\begin{tabular}{ccc}
\hline & Chi-Square Value & $p$-Value \\
\hline 1. FIT & 61.48 & $2.84 \times 10^{-13}$ \\
2. End of the Payback Period & 91.64 & $9.71 \times 10^{-20}$ \\
3. Promotion at the End of the Payback Period & 28.54 & $2.80 \times 10^{-6}$ \\
4. Expected Ideal Lifespan & 35.31 & $1.05 \times 10^{-7}$ \\
\hline
\end{tabular}

Note: FIT-feed-in-tariff.

\subsection{Waste Generation Estimation \\ 3.2.1. Installation Scenario}

We followed the JPEA scenarios [1] for all of Japan and allocated it proportionally using the share of installed capacity in each municipality in Tokyo prefecture as of March 2019 and estimated the future installation from 2019 to 2060. The reason why we need a municipality-level scenario is to reflect the different shares of age groups for municipalities. We analyzed the existing installation information and determined that the average capacity of PV panels installed in housings was 3 to $7 \mathrm{~kW}$. By simply taking the average of 3 and 7, after 2019, we assumed that all housing will install the same size of panels with a capacity of $5 \mathrm{~kW}$. By dividing the estimated installed capacity with $5 \mathrm{~kW}$, we obtained future installation scenarios in units of the number of households that newly installed PV panels. The estimated installation scenario is shown in Figure 2, along with the results of the waste generation scenarios. 


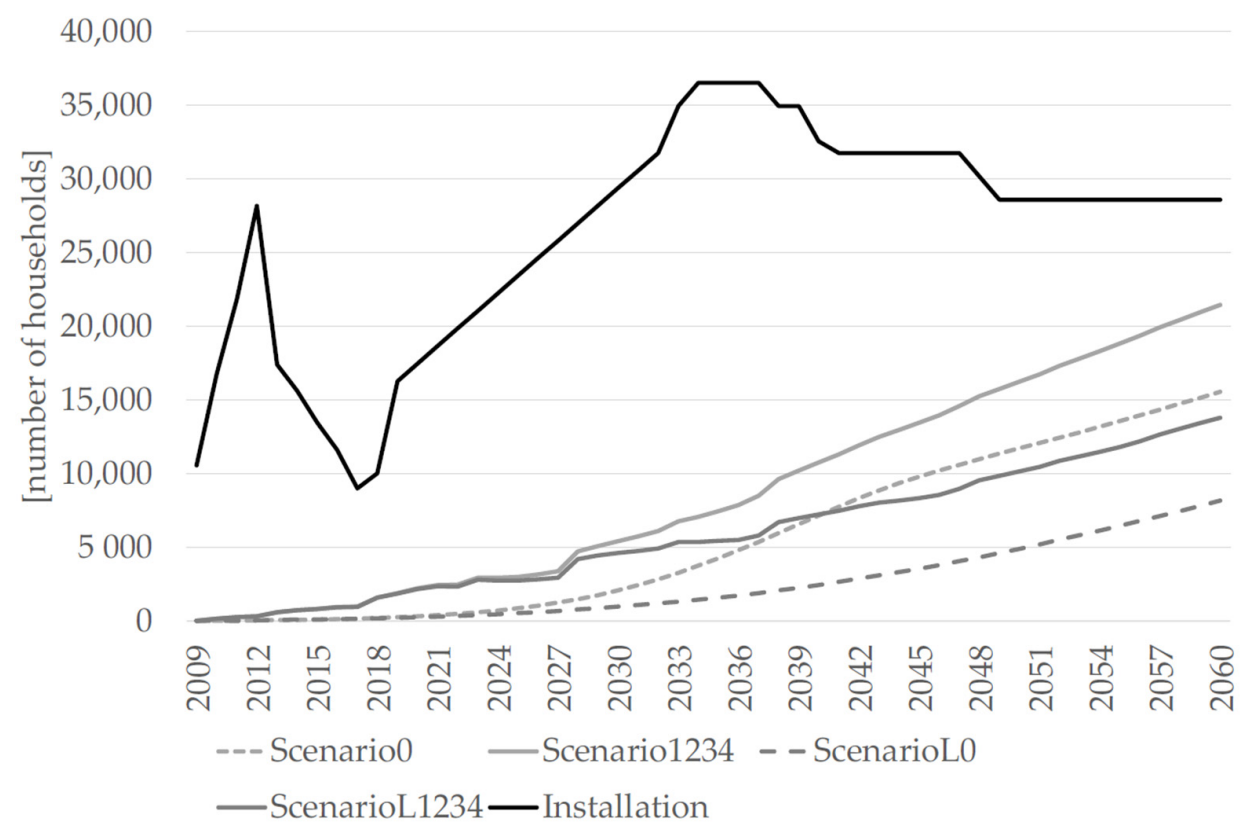

Figure 2. Waste generations between 2009 to 2050 for four scenarios.

\subsubsection{Probability Density Function (PDF)}

To use the results of the questionnaire survey, we first assumed that there were 709 households. Then, based on the questionnaire survey results, we recorded the year only for those who answered that they would consider replacement or disposal in one of the four decision-making scenarios. The end of the FIT period is the same for all households, but the payback period and expected ideal life of the panel were also obtained in our survey, and therefore vary among households. We obtained four at maximum as the potential time when the household's PV panel reaches EOL stage and is considered as waste by their own decision making. The earliest time was chosen as the timing for the household for their decision of EOL panel generation even if it has not failed.

We had one distribution for the duration of use of the 709 samples. Even though we can take the whole samples as one distribution, as mentioned in Section 3.1, the age group causes significant differences in the owners' decision making. Therefore, 709 samples were divided into four age groups and four distributions were obtained. The groups consisted of 157 (age 25-39), 176 (age 40-49), 190 (age 50-59), and 206 (age 60 and older) samples. Then, for all 709 households, according to the assumed Weibull distributions, the expected failure timings for both PV panels and housing were randomly and independently assigned. Finally, among the durations due to households' decision making, panel failure, and housing failure, the earliest duration was recorded as the EOL generation timing for the household. However, as previously mentioned, the durations due to panel failure and housing failure were generated independently and randomly. The combination of these two durations and that of the questionnaire results are not uniquely determined. Therefore, a Monte Carlo simulation was employed to randomly generate the timings due to the two failures and was independently run 100 times. Fortunately, there were no significant differences in each simulation run. Therefore, by taking the average generation for each year and adjusting the total number of generations to match the sample size, we finally obtained the pdf for household PV panels in Tokyo.

\subsubsection{Waste Generation}

An installation scenario was prepared for each municipality in the Tokyo metropolitan area. Different pdfs were prepared for four different age groups. Assuming that the population shares between each age group remained constant for each municipality, we applied four pdfs depending on the population shares on each year's installation. We prepared different sets of scenarios for the combination of the six reasons considered: panel 
failure, housing failure, the owners' decision making at the end of FIT period, at the end of the Payback Period, promotion at the end of the Payback Period, and the end of expected ideal lifespan. The scenario sets are listed in Table 2.

Table 2. Reasons considered in each scenario setting.

\begin{tabular}{ccccc}
\hline Scenario & $\mathbf{0}$ & $\mathbf{1 2 3 4}$ & L0 & L1234 \\
\hline Panel Failure & $\mathrm{x}(30$ years & $\mathrm{x}(30$ years & $\mathrm{x}(57$ years & $\mathrm{x}(57$ years \\
average life $)$ & average life $)$ & average life $)$ & average life $)$ \\
Housing Failure & $\mathrm{x}$ & $\mathrm{x}$ & $\mathrm{x}$ & $\mathrm{x}$ \\
1. FIT & & $\mathrm{x}$ & & $\mathrm{x}$ \\
2. PP & & $\mathrm{x}$ & & $\mathrm{x}$ \\
3. PPP & & $\mathrm{x}$ & $\mathrm{x}$ \\
4. Ideal Life & & & & \\
\hline
\end{tabular}

Note: In the table, " $\mathrm{x}$ " means the factor considered. Therefore, " 0 ", in scenario names means not considering any decision making factor, and " 1 ", " 2 ", " 3 ", and " 4 " means considering "FIT", "PP", "PPP", and "Ideal Life", respectively, as shown in Table 2. FIT, PP, and PPP denote the end of the feed-in-tariff (FIT) period, the end of the payback period (PP), and the promotion at the end of the payback period (PPP.). Additionally, "L" means 57 years average life assumed for PV panel for its Weibull parameter estimation, otherwise 30 years is assumed.

The waste generation scenarios are shown in Figure 2. The vertical axis has the unit of "number of households." By comparing Scenarios 0 and L0, two different parameter sets for the Weibull distribution of the PV panel resulted in significant differences. However, the comparison between Scenarios 1234 and L1234 showed a much smaller difference, especially before 2030 . The pdf obtained for these two scenarios have multiple generation peaks during the first 20 years, which are mainly due to owners' decision making rather than mechanical failures. The largest peak appeared 10 years after installation, when the FIT period ended. The other peaks observed were that of the payback period and expected ideal life.

In addition, as shown in the installation scenario in Figure 2, we observed an installation peak around 2012, which corresponds to the FIT rate change as shown in Figure 3. The results suggest that, until 2030, most of the waste panels were installed at the first peak around 2012 and generated by the owner's decisions rather than mechanical failures. Once the panels installed during the first installation peak became waste, a much smoother trend in waste generation was observed, reflecting the gradual increase in installation.

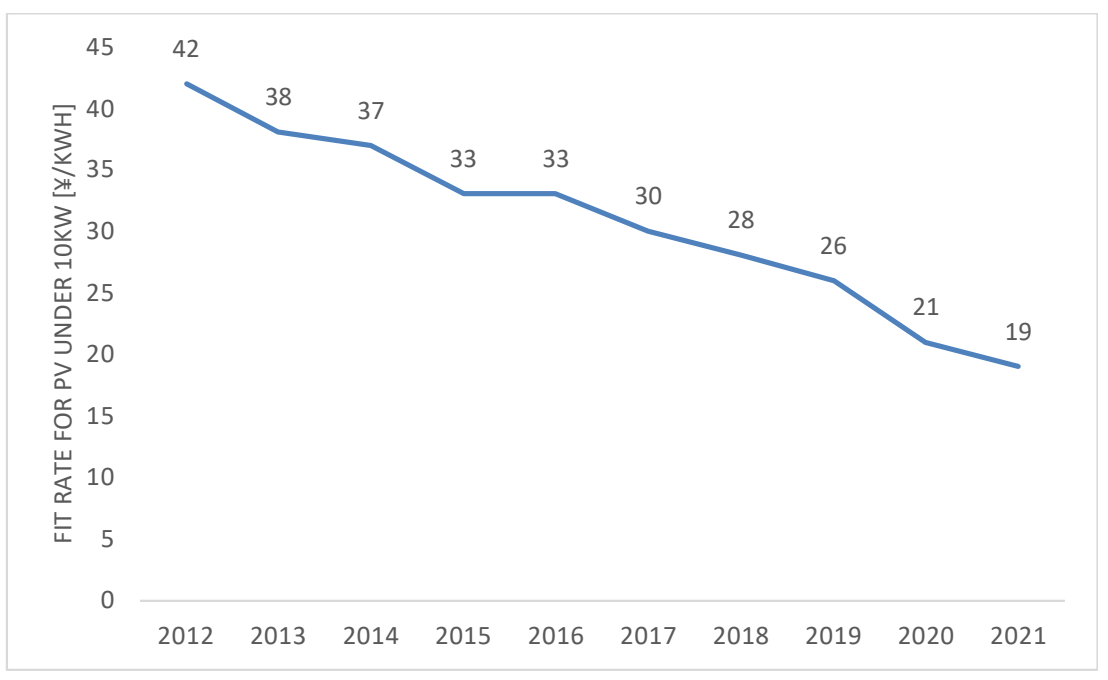

Figure 3. Historical FIT rate for the panels with the capacity below $10 \mathrm{~kW}$.

\subsubsection{Reusable Panels}

Finally, early generation before mechanical failure means that a significant number of "unbroken" panels will emerge as waste, which are potentially reusable. In this study, all 
generated EOL panels have their own reasons why they were disposed of; therefore, the amount of broken panels and unbroken potentially reusable panels can be calculated. The results for Scenarios 0 and 1234 are shown in Figure 4.

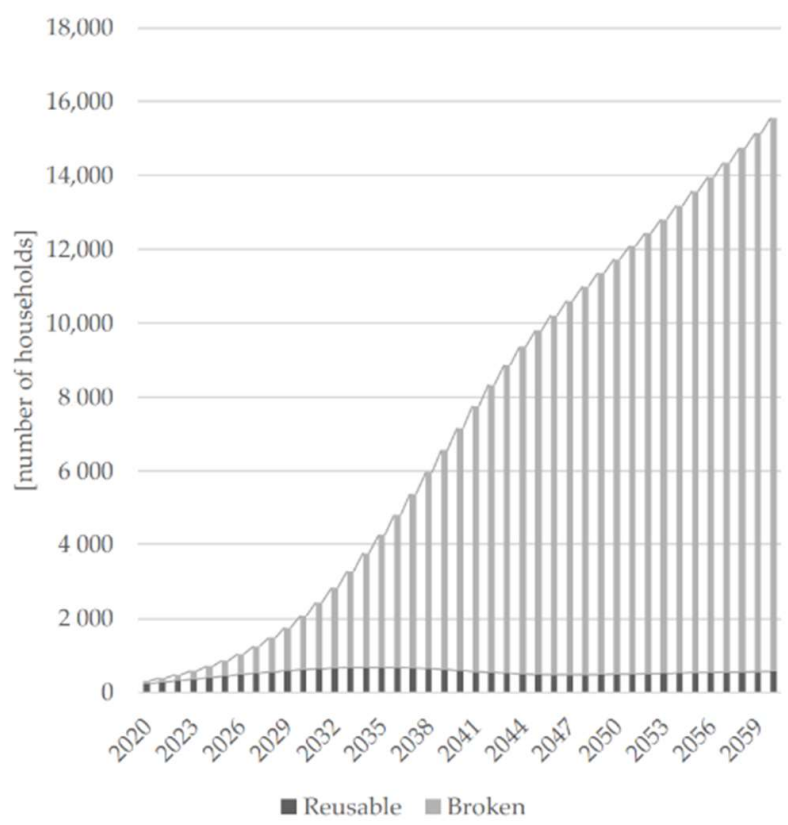

(a)

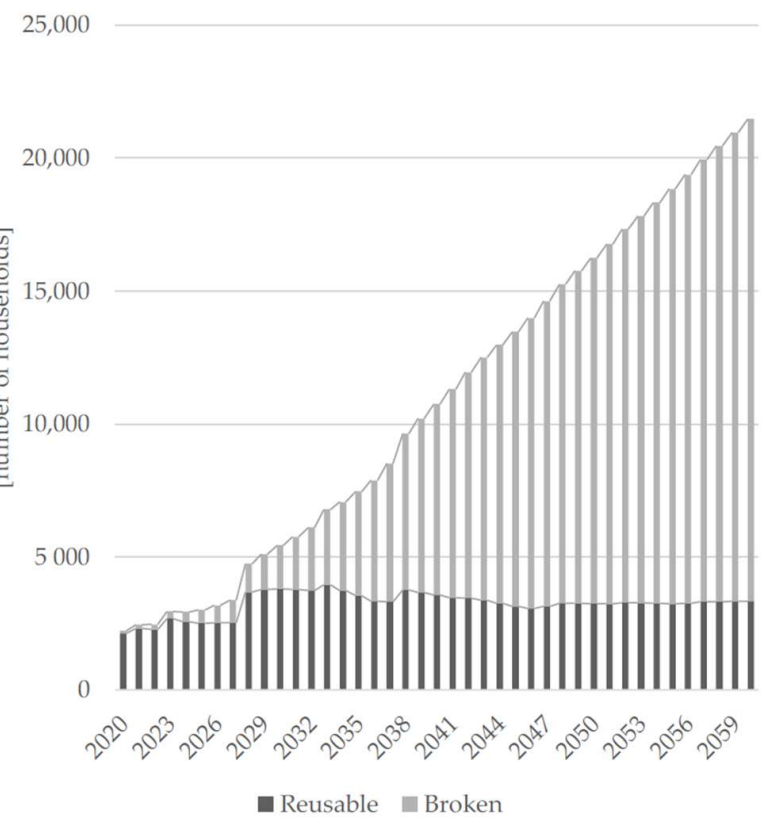

(b)

Figure 4. Amount of waste panel generation divided by broken and reusable panels; (a) Scenario 0 and (b) Scenario 1234.

Figure 4a shows that a large number of panels were wasted because of housing failure and are therefore reusable. This is especially true in the early days. This is partially because we assume that a non-negligible number of PV panels are installed on the roof of existing housing following the results our survey, whose remaining life is not necessarily long. More importantly, owners' decision making has resulted in a significant number of potentially reusable waste panels, especially in the early stages of generation.

\section{Discussion}

The primary purpose of this study is to quantify the potential impact of owners' decision making regarding disposal/replacement of solar PV panels on waste PV panel generation, using a case study of rooftop PV panels in Tokyo. To our knowledge, quantifying the impact of consumer decision making on waste generation has not previously been attempted for PV panels.

The result shown in Figure 2 demonstrates that the impact of owners' decision making is hardly ignorable. The most frequently cited EOL panel generation estimation in Japan is that from the Ministry of Environment (MOE), which assumes a single fixed duration for all panels [20]. It estimates that the total amount of EOL panels from Japan does not provide any estimate for rooftop panels; therefore, the result is not comparable with this study. Nonetheless, their result and our results for Scenarios 0 and L0 can be compared. Our results have a smoother trend simply because which assumes Weibull distribution for the duration in use; therefore, the huge fluctuation in installation amount is smoothed at the end of the duration, while MOE's estimation assumed single fixed duration therefore the fluctuation directly appeared at the end of the duration. This is the expected outcome given estimations for other countries, which have similar assumptions, such as that by Santos and Alonso-García [13].

The difference between Scenarios 0 and 1234 and Scenario L0 and L1234 seems significant. Considering owners' decision making, the EOL generation will be much earlier than without the consideration, which has important meanings for policy making. It also 
should be noted that our results for Scenarios 0 and L0 suggest that we need to have a better understanding of the mechanical life of the panels and the definition of "failure". Even though the consideration of owners' decision making is important and meaningful, the assumption for pdf by mechanical failures is essential for accurate EOL generation estimation. In the case of the panels, it was difficult to see them completely broken. A panel can be called "failed" when its efficiency decreases beyond a certain threshold value, which will be defined.

As already mentioned, Japan has not yet prepared a strict framework for waste PV management. Interviews with multiple stakeholders suggested that there are some practices of inappropriate treatment and/or landfilling as well as unrecognized exports. Currently, the amount of PV waste generated is relatively small; therefore, all governments should take advantage of this opportunity to develop and establish a framework for waste management. Once the level of generation becomes huge, we need to prepare a RL system with appropriate control. In particular, in the case of waste panels from households, a small number of panels will be generated from a significant number of generators. In crowded cities such as Tokyo, there are many factors that reduce the efficiency of logistics, such as the fact that the roads are not always wide and often cause huge traffic jams. Therefore, it is necessary to design an entire RL system, including the installation of collection points. Now, early generation means that these social system designs should also be prepared much earlier than expected. Therefore, we recommend that policymakers work on this issue as early as possible.

The decision on reusability was extremely difficult and, therefore, the amount of reusable PV panels generated was overestimated. Our results simply show the number of unbroken panels and, therefore, the maximum potential reusable amount of panels. However, our social system design should consider potential reuse. The panels that need to be reused must be handled with care, which requires two transportation systems, one for reusable panels and the other for non-reusable panels. This will reduce transportation efficiency; therefore, more careful consideration is needed.

\section{Conclusions}

In this study, we surveyed the potential consumer decision making on the replacement/disposal of PV panels before the panels fail. It was found that the younger generation is more likely to consider replacing or disposing of panels at various times before they fail. Then, considering these owners' decision making may cause earlier waste panel generation compared with the case where we only assume the mechanical failure of panels and housing. This also means a huge number of potentially reusable panel generations.

Our estimation of waste panel generation according to owners' decision making, other than mechanical failures should be considered as the maximum potential. Our survey involved asking consumers to predict their likely future behavior with regard to PV panel disposal/replacement. Our data are therefore of a predictive nature, which is a limitation of this study.

Nonetheless, the results of this study suggest that policy makers should prepare an appropriate recycling social system much earlier than is currently being prepared, considering the possible reuse of PV panels. This is also a good match for the current social situation, which is oriented toward a circular economy. Finally, researchers should further explore consumers' decision making regarding the replacement and/or disposal of PV panels for reasons other than panels' mechanical failures, while more explicit inclusion of financial decision making of the owners are another possible path to tackle this issue.

Author Contributions: Conceptualization, S.M.; methodology, S.M., H.Y., T.T.; validation, S.M., H.Y.; writing-original draft preparation, T.T.; writing—review and editing, S.M.; supervision, S.M.; project administration, S.M.; funding acquisition, S.M. All authors have read and agreed to the published version of the manuscript. 
Funding: This research was performed under the project proposal scheme by university researchers: Project for Advanced Circulating of Photovoltaic Modules (2019-2021), funded by Tokyo Metropolitan Government.

Institutional Review Board Statement: The study was conducted according to the guidelines of the Declaration of Helsinki, and approved by the Ethics Committee of Graduate School of Engineering, The University of Tokyo (KE19-58 and 26 November 2019).

Informed Consent Statement: Informed consent was obtained from all subjects involved in the study.

Data Availability Statement: Not applicable.

Acknowledgments: The authors thank all respondents, both in our stakeholder survey and our online consumer survey. We also thank our research project members for their meaningful comments in project meetings.

Conflicts of Interest: The authors declare no conflict of interest.

\section{Appendix A}

Table A1. Selected questions used in our analysis.

\begin{tabular}{|c|c|}
\hline \multicolumn{2}{|r|}{ Screening Questions: } \\
\hline S1 & What is your postal code? \\
\hline $\mathrm{S} 2$ & Have you ever installed PV panels at your house? \\
\hline S3 & Have you ever detached PV panels from your house? \\
\hline S4 & How many years have passed since your house was built? \\
\hline \multicolumn{2}{|r|}{ Only those who answered yes to question S2 should answer the following questions: } \\
\hline Q1 & When did you install the PV panels of your house? \\
\hline Q2 & Please tell us the capacity and the number of panels you installed. \\
\hline Q3 & $\begin{array}{l}\text { What is the age of the person who decided to install the panels? If this was decided not } \\
\text { by any single person but the family as a whole, please say so. }\end{array}$ \\
\hline Q4 & Please tell us the expected payback period of the PV panels. \\
\hline Q5 & $\begin{array}{l}\text { How many years do you believe that you can continue to use the current PV panels? } \\
\text { Please provide the number of years since installation. }\end{array}$ \\
\hline Q6 & $\begin{array}{l}\text { Please imagine you are now facing the following scenario. Then, please choose that } \\
\text { behavior you would most likely take from the list that follows. }\end{array}$ \\
\hline Q6-1 & $\begin{array}{l}\text { It is the end of the FIT period. [Keep using the existing panel(s)./Replace with new } \\
\text { panel(s)./Detach and dispose of panel(s)./Other/No plan./Difficult to answer] }\end{array}$ \\
\hline Q6-2 & $\begin{array}{l}\text { At the end of the payback period [Keep using the existing panel(s)./Replace with new } \\
\text { panel(s)./Detach and dispose of panel(s)./Other/No plan./Difficult to answer] }\end{array}$ \\
\hline Q6-3 & $\begin{array}{l}\text { A sales person approaches you to promote replacement of your panel(s) at the end of the } \\
\text { payback period. [Keep using the existing panel(s)./Replace with new panel(s)./Detach } \\
\text { and dispose of panel(s)./Other/No plan./Difficult to answer] }\end{array}$ \\
\hline Q6-4 & $\begin{array}{l}\text { When the time you answer in Q5 passes. [Keep using the existing panel(s)./Replace with } \\
\text { new panel(s)./Detach and dispose of panel(s)./Other/No plan./Difficult to answer] }\end{array}$ \\
\hline & Please provide the following demographic variables: \\
\hline
\end{tabular}

\section{References}

1. Japan Photovoltaic Energy Association (JPEA). JPEA PV Outlook 2050. 2020. Available online: https://www.jpea.gr.jp/wpcontent/themes/jpea/pdf/pvoutlook2050_2020.pdf (accessed on 31 August 2021). (In Japanese)

2. Elshkaki, A.; Shen, L. Energy-material nexus: The impacts of national and international energy scenarios on critical metals use in China up to 2050 and their global implications. Energy 2019, 180, 903-917. [CrossRef]

3. Moreau, V.; Dos Reis, P.; Vuille, F. Enough Metals? Resource Constraints to Supply a Fully Renewable Energy System. Resources 2019, 8, 29. [CrossRef]

4. Chowdhury, M.S.; Rahman, K.S.; Chowdhury, T.; Nuthammachot, N.; Techato, K.; Akhtaruzzaman, M.; Tiong, S.K.; Sopian, K.; Amin, N. An overview of solar photovoltaic panels' end-of-life material recycling. Energy Strateg. Rev. 2020, 27, 100431. [CrossRef] 
5. Muteri, V.; Cellura, M.; Curto, D.; Franzitta, V.; Longo, S.; Mistretta, M.; Parisi, M.L. Review on Life Cycle Assessment of Solar Photovoltaic Panels. Energies 2020, 13, 252. [CrossRef]

6. Mahmoudi, S.; Huda, N.; Alavi, Z.; Islam, M.T.; Behnia, M. End-of-life photovoltaic modules: A systematic quantitative literature review. Resour. Conserv. Recycl. 2019, 146, 1-16. [CrossRef]

7. Murakami, S.; Oguchi, M.; Tasaki, T.; Daigo, I.; Hashimoto, S. Lifespan of commodities, part I: The creation of a database and its review. J. Ind. Ecol. 2010, 14, 598-612. [CrossRef]

8. Oguchi, M.; Murakami, S.; Tasaki, T.; Daigo, I.; Hashimoto, S. Lifespan of commodities, part II: Methodologies for estimating lifespan distribution of commodities. J. Ind. Ecol. 2010, 14, 613-626. [CrossRef]

9. Hocine, L.; Mounia Samira, K. Optimal PV panel's end-life assessment based on the supervision of their own aging evolution and waste management forecasting. Sol. Energy 2019, 191, 227-234. [CrossRef]

10. Jordan, D.C.; Kurtz, S.R. Photovoltaic Degradation Rates-an Analytical Review. Prog. Photovolt. Res. 2013, 21, 12-29. [CrossRef]

11. IRENA and IEA-PVPS. End-of-Life Management: Solar Photovoltaic Panels; International Renewable Energy Agency and International Energy Agency Photovoltaic Power Systems: Abu Dhabi, United Arab Emirates, 2016.

12. Paiano, A. Photovoltaic waste assessment in Italy. Renew. Sustain. Energy Rev. 2015, 41, 99-112. [CrossRef]

13. Santos, J.D.; Alonso-García, M.C. Projection of the photovoltaic waste in Spain until 2050. J. Clean. Prod. 2018, 196, 1613-1628. [CrossRef]

14. Woidasky, J.; Cetinkaya, E. Use pattern relevance for laptop repair and product lifetime. J. Clean. Prod. 2021, $288,125425$. [CrossRef]

15. Yamamoto, H.; Murakami, S. Product obsolescence and its relationship with product lifetime: An empirical case study of consumer appliances in Japan. Resour. Conserv. Recycl. 2021, 98, 105798. [CrossRef]

16. Guo, X.; Yan, K. Estimation of obsolete cellular phones generation: A case study of China. Sci. Total Environ. 2017, 575, 321-329. [CrossRef] [PubMed]

17. Ministry of Economy, Trade and Industry, Japan. Documents for Procurement Price Calculation Committee. Available online: https:/ / www.meti.go.jp/shingikai/santeii/pdf/003_03_00.pdf (accessed on 27 August 2021). (In Japanese)

18. Ministry of Environment, Japan. Forecasting Future Introduction of Solar Power Generation and Associated Information. Available online: https:/ / www.env.go.jp/earth/report/h26-01/ref04.pdf (accessed on 27 August 2021). (In Japanese)

19. Omi, Y.; Kurita, N. Simulation of Building Residual Ratio Under the Trends in Longer Life of Buildings. J. Archit. Plan. (Trans. AIJ) 2010, 75, 2459-2465. [CrossRef]

20. Ministry of Environment, Japan. The Report for Reusing, Recycling and Appropriate Management of EOL PV Panels and Other Renewable Power Plants. (In Japanese). Available online: https:/ /www.env.go.jp/press/files/jp/27519s.pdf (accessed on 31 August 2021). 